\title{
Land Cover Change Detection Analysis for Landslide Monitoring Using SPOT-5 Satellite Images.
}

\author{
Noraisyah Tajudin, Norsuzila Ya'acob, Darmawaty Mohd Ali, and Nor Aizam Adnan
}

\begin{abstract}
Landslides have become a common disaster in Malaysia, the incident occurred according to human activity in economic development. Deforestation, urbanization, development of hill slopes and other human land use have given rise to increased risks of landslides. This paper reports the monitoring of the landslide by applying Land Cover (LC) change detection by utilizing two multispectral satellite imagery SPOT 5 for the year 2005 and 2014. ArcMap 10.2.2 software was used in the image processing using Maximum likelihood classification. This study is conducted in Ulu Kelang, Selangor which is located at hilly and sloppy terrain surround by forestry. The results show the method of LC changes and factor of the landslide can be justified via remote sensing image within 10 years' time. The accuracy of image classification was showed an overall accuracy of $95 \%$ (2005) and 93\% (2014), while kappa coefficient indicates the method of classification and the images used were excellent quality. During this study period, an urban area has shown an increase of $14.143 \%$, while the green area had decreased by $8.432 \%$ due to an increase of interest in urbanization development. There were twelve landslides recorded during the years 2006 to 2014, about $\mathbf{9 1 . 6 6 \%}$ landslide events were affected build up area which were residential area and road. This analysis showed that human influence or activity could be contributing to landslide occurrences. Therefore, the urbanization development is very important to have proper planning to reduce the susceptibility of landslide occurrences in Ulu Kelang, Selangor.
\end{abstract}

Keywords-Landslide, Remote Sensing, Land Cover, Change Detection, SPOT Satellite Images.

\section{INTRODUCTION}

Landslides are defined as the movement of a mass of rock, debris or earth downslope influenced by gravity. The oftentriggering factors of landslide including intense or prolonged rainfall, earthquakes, rapid snow melting, volcanic activity and variety of anthropogenic activities.

Landslide disaster may affect human life, property and environment [1]. In Malaysia, most of the landslides or slope failure incident occurred due to intense rainfall and urban development over hillside areas [2].

This manuscript is submitted on 28th January 2020 and accepted on 9th July 2020. Noraisyah Tajudin, Norsuzila Ya'acob and Darmawaty Mohd are with the Faculty of Electrical Engineering, Universiti Teknologi MARA, 40450 Shah Alam, Selangor (email: tnoraisyah@gmail.com)

Nor Aizam Adnan is from Faculty of Architecture, Planning and Surveying, Universiti Teknologi MARA, 40450 Shah Alam, Selangor.

1985-5389/C 2021 The Authors. Published by UiTM Press. This is an open access article under the CC BY-NC-ND license (http://creativecommons.org/ licenses/by-nc-nd/4.0/).
The most tragic landslide incident was the collapse of the 14storey Block A of the Highland Tower in Ulu Kelang, Selangor in December 1993 due to the retrogressive failure of the cut slope behind the tower.

Landslide monitoring is the comparison of whatsoever landslide conditions over time. The monitoring landslide activity over an extensive area is important to identify "cause" and "effect" of landslide, detection and prediction of the future landslide; provide alert and alarm signals to ensure the safety of population and infrastructures [3]. Earth Observation-based on satellite remote sensing is useful in landslide monitoring due to its fast response, wide field of view, and relatively low cost [4][5]. Remote sensing offers a wide range of spatial, spectral and temporal parameters because it uses sensors or detector which is on board of satellite or aircraft. Techniques used in remote sensing include interpreting the aerial photo, satellite image processing and interferometric synthetic aperture radar (lnSAR). Later, some improvement has been achieved in remote sensing; light detection ranging (LIDAR) has been used to investigate the landslide. Remote sensing imageries had a capability in acquiring the past and present in mapping landslide occurrence [6][7][8].

Change detection is a technique used in remote sensing to measure surface processes for volumetric change such as map erosion and deposition. Methods of change detection are usually divided into pixel comparison directly and postclassification comparison [9][10][11]. Change detection is useful in many applications related to LC changes, such as shifting cultivation and landscape changes, land degradation and desertification, coastal change and urban development Image pre-processing, deforestation, habitat fragmentation and other cumulative changes.[12][13][14][15]. Some studies have indicated that human-induced land cover change (LCC) contributes significantly to the initiation and reactivation of landslides especially in populated regions, where landslides represent a major risk to infrastructure, human settlements and people [16][17].

In this paper, we propose a method that fuses LC change detection and Maximum likelihood supervised classification based on multispectral satellite imagery SPOT 5 data. We analyze the LC classification, investigate, and validate the spatial probability factor of landslide and LC change detection by using the powerful tools ArcMap 10.2.2 software. 


\section{Methodology}

\section{A. Study area and Data}

Ulu Kelang, Selangor has been selected as study area which is located at coordinate $3^{\circ} 12^{\prime} 3.6^{\prime \prime} \mathrm{N}$ and $101^{\circ} 46^{\prime} 1.2^{\prime \prime} \mathrm{E}$, is an urbanization area which has very high demands on its land property and housing development, particularly at the hillside area as shown in Figure 1 [18].

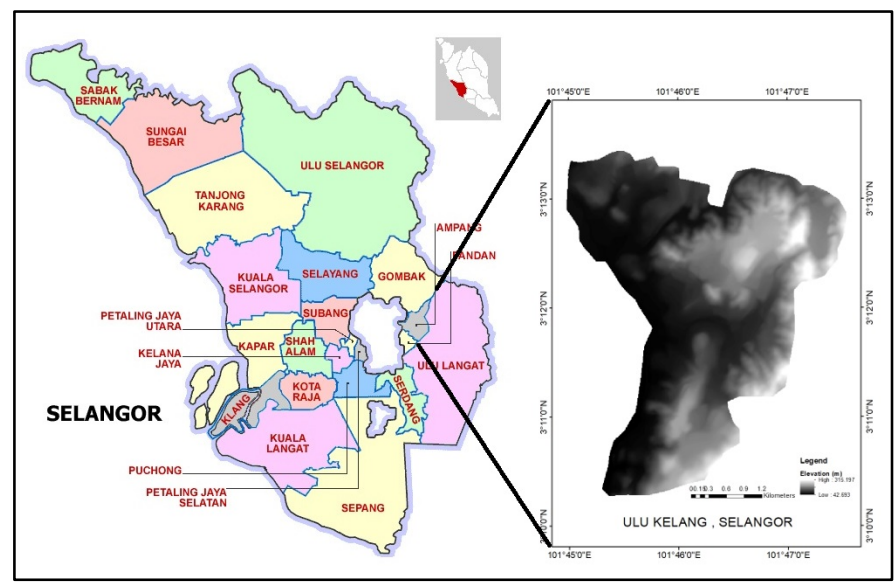

Figure 1: The location of Ulu Kelang, Selangor

This study was conducted based on the landslide occurred between the year 2006 to 2014. The SPOT 5 satellite images with the specification of 3 bands and vegetation sensor with the 5 meter resolution, path (270) and row (343) have been used in the classification process. Two satellite images were selected in the year 2005 and 2014. The satellite images are given with compliment from the Malaysian Space Agency (MYSA).

\section{B. Method}

Basically, data/image processing consists of three stages, in which, phase one is data/image collection, phase two is data/image processing, and phase three is result and analysis. In this study, ArcMap 10.2.2 Software was selected to process and analyze the LC map obtain from SPOT satellite images. Figure 2 shows the flowchart of image processing for LC mapping. The image processing for SPOT-5 images was started with georeferencing process which the spheroid is set to Modified Everest, the Datum is set to Kertau 1948 and RSO type is set to Malaysia. In image subsetting stage, SPOT 5 images were subsetting into Ulu Kelang area covers by approximately 15.9 $\mathrm{km}^{2}$. The processes were followed with haze reduction to enhancement the image quality and replace the missing or bad line to normalize radiometry for the clearest portion of image [19].

The classification of LC was classified using Maximum likelihood supervised classification. In Supervised Classification, the classification process has been controlled by creating, managing, evaluating, and editing signatures using the Signature Editor. Signatures are specific areas to which the names are assigned for supervised classification. Signatures are used to break the different classes like a forest, cultivated, water and the like classes into as many subclasses as per classification requirement. The supervised classification is the most common method in obtaining land use/cover information [12].

The accuracy assessment was applied for validation of the LC classification using Kappa statistical analysis based on 103 random points that were identified and located using a stratified random method in ArcMap 10.2.2 software to represent the different LC classes of the area. The ground truth point's data and the classification results were compared and statistically analyzed using error matrices. After the LC classification, the SPOT 5 images were combined to highlight the difference in change detection.

The LC change detection analysis has been compared to the landslide events that occurred in year 2006 to 2014. This comparation was conducted to investigate the relationship between LC classification and landslide occurrences at Ulu Kelang Selangor.

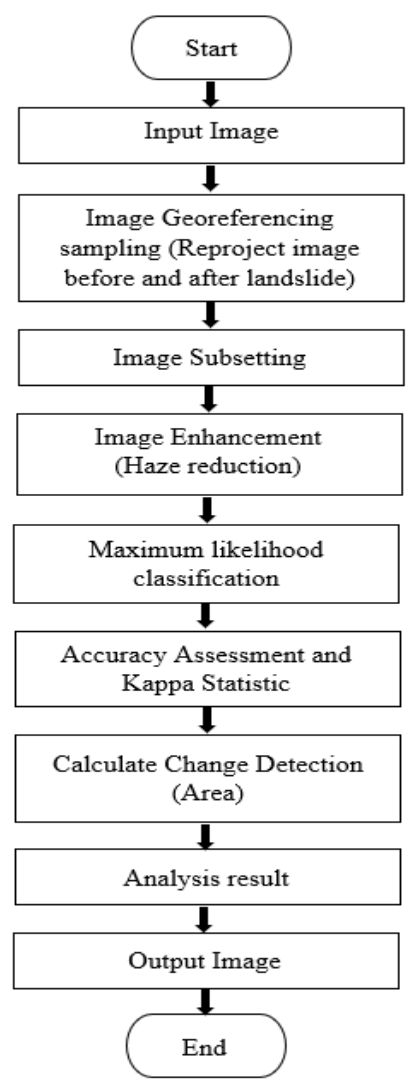

Figure 2: The flowchart of image processing for LC mapping.

\section{RESUlTS AND DISCUSSION}

\section{A. Land Cover Classification}

The SPOT 5 images for LC change detection analysis between 2005 to 2014 were processed part by part. The processed were conducted using ArcMap 10.2.2, which including georeferencing, subset, haze reduction, supervised classification and recode. Then, the analysis of LC mapping in the year 2005 and 2014 was combined to highlight the difference. Five classes have been identified in the Maximum 
likelihood supervised classifications for LC mapping in Ulu Kelang, Selangor. The LC mapping classification system was adopted from USGS's Anderson Classification System [20]. The classes were divided into Green area (green), water bodies (Blue), Developing area (Yellow) and Build Up area (Red). The description of identified LC classes is shown in Table 1. While the recode images or LC mapping classification for 2005 and 2014 were shown in Figure 3 and Figure 4.

\begin{tabular}{|c|c|c|}
\hline Code & LC Class & Description \\
\hline 1 & Green Area & $\begin{array}{c}\text { Forest, Vegetation area and Recreation } \\
\text { Park }\end{array}$ \\
\hline 2 & Water Bodies & Lakes, Pool and Waste reclamation plant \\
\hline 3 & $\begin{array}{l}\text { Developing } \\
\text { Area }\end{array}$ & $\begin{array}{c}\text { Construction areas for residential and } \\
\text { commercial; and bare soil. }\end{array}$ \\
\hline 4 & Build Up & $\begin{array}{l}\text { Residential, commercial, and service; } \\
\text { transportation, communication and utilities; } \\
\text { industrial and commercial complexes, } \\
\text { Institutions and places of worship. }\end{array}$ \\
\hline
\end{tabular}

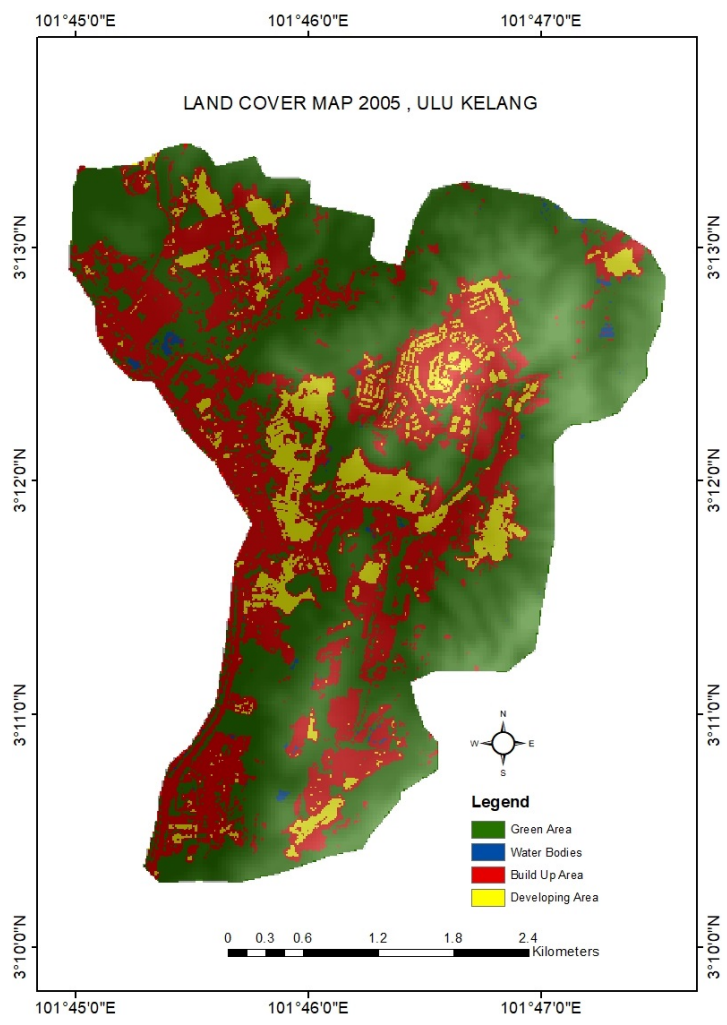

Figure 3. LC map of Ulu Kelang, Selangor in year 2005

\section{B. Accuracy Assessment and Kappa Statistics}

In the accuracy assessment, 101 points were selected as references for images in Fig. 3 and Fig. 4. The overall classification accuracy for images in Fig. 3 is $95 \%$ in the year 2005 and Fig 4 is $93 \%$ in the year 2014. While the assessment based on kappa statistics shows, both images are excellent quality where the value of Kappa Statistics is 0.929 in the year 2005 and 0.898 in the year 2014, as shown in Table 2 and Table 3.

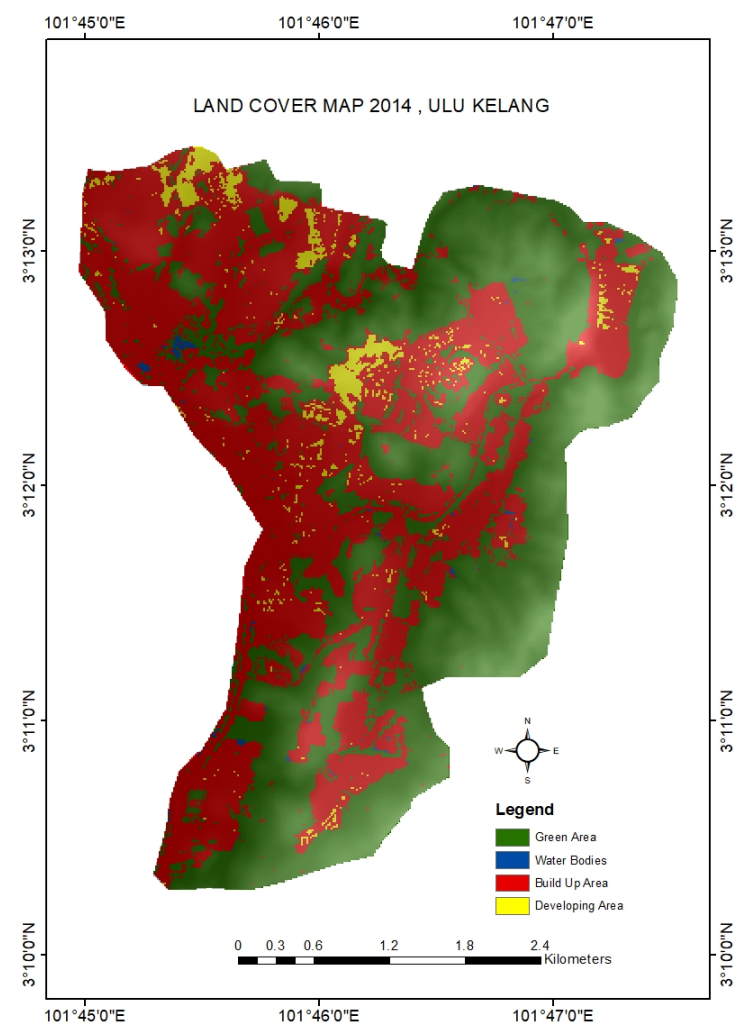

Figure 4. LC map of Ulu Kelang, Selangor in year 2014

TABLE 2: USER AND PROCEDURE ACCURACY ASSESSMENT FOR UlU KELANG, SELANGOR

\begin{tabular}{lcccc}
\hline \hline \multirow{2}{*}{$\begin{array}{c}2005 \\
\text { Year / Land Cover }\end{array}$} & $\begin{array}{c}\text { User } \\
\text { Accuracy } \\
(\%)\end{array}$ & $\begin{array}{c}\text { Procedure } \\
\text { Accuracy } \\
(\%)\end{array}$ & $\begin{array}{c}\text { User } \\
\text { Accuracy } \\
(\%)\end{array}$ & $\begin{array}{c}2014 \\
\text { Procedure } \\
\text { Accuracy } \\
(\%)\end{array}$ \\
\hline \hline Green Areas & 97 & 92 & 97 & 95 \\
Water Bodies & 100 & 100 & 100 & 100 \\
Build Up & 96 & 96 & 91 & 93 \\
Developing Areas & 91 & 97 & 86 & 86 \\
\hline \hline
\end{tabular}

TABLE 3: ACCURACY ASSESSMENT AND KAPPA STATISTICS FOR ULU KELANG, SELANGOR

\begin{tabular}{cccl}
\hline \hline Year & $\begin{array}{c}\text { Overall Classification } \\
\text { Accuracy }\end{array}$ & $\begin{array}{c}\text { Overall Kappa } \\
\text { Statistics }\end{array}$ & Kappa Quality \\
\hline 2005 & $95 \%$ & 0.929 & Excellent \\
2014 & $93 \%$ & 0.898 & Excellent \\
\hline \hline
\end{tabular}

\section{Land Cover Change Detection and Factor of Landslide.}

The LC change detection from the SPOT 5 satellite image gives the information about the factor of landslide occurrences in more detail. The analysis is based on the increment and decrement of the area within 10 years from the year 2005 to 2014. Table 4 presents the changes in the scope of area in unit $\mathrm{km}^{2}$. The most of study area is covered by green area where is located adjacent to the forest reserve of Ampang and Ulu Gombak. The SPOT 5 image of 2005 indicated that; green area, water bodies, developing area and build up an area are about 
$57.419 \%, \quad 0.447 \%, \quad 8.806 \%$ and $33.329 \%$ respectively. Similarly, in 2014 green area showed high coverage with $48.987 \%$ followed by a build-up area with covers of $47.472 \%$.

As shown in Table 4, the major types of LC showed in both years is a green area where is most of the area is forest, followed by a build-up area and developing area. The results showed the build-up area was increased by $14.143 \%$ within 10 years from the year 2005 to 2014. This is due to an increase in urban developments in Ulu Kelang area, especially in a hilly area. While the developing area was decreased by $5.573 \%$, where it indicates that most of the developing phase is completed and change to build up area. According to the LC changes from the year 2005 to 2014, green area and water bodies are showed decrement where is the changed are $8.432 \%$ and $0.139 \%$. This decrement is caused by the growing of build-up area which is demanding for a residential area.

\begin{tabular}{cccccc}
\multicolumn{7}{c}{ TABLE 4: THE INCREASING AND DECREASING OF Ulu KELANG, SELANGOR } \\
\hline \hline LC Type & $\begin{array}{c}\text { Area } \\
\left(\mathrm{km}^{2}\right)\end{array}$ & $\begin{array}{c}\text { Percentage } \\
(\%)\end{array}$ & $\begin{array}{c}\text { Area } \\
\left(\mathrm{km}^{2}\right)\end{array}$ & $\begin{array}{c}\text { Percentage } \\
(\%)\end{array}$ & $\begin{array}{c}\text { Change in \% } \\
\text { from 2005 to } \\
2014\end{array}$ \\
\hline \hline $\begin{array}{c}\text { Green } \\
\text { Areas }\end{array}$ & 9.168 & 57.419 & 7.822 & 48.987 & $(-) 8.432$ \\
$\begin{array}{c}\text { Water } \\
\text { Bodies }\end{array}$ & 0.071 & 0.447 & 0.049 & 0.308 & $(-) 0.139$ \\
$\begin{array}{c}\text { Developing } \\
\text { Areas } \\
\text { Build Up } \\
\text { Areas }\end{array}$ & 1.406 & 8.806 & 0.516 & 3.233 & $(-) 5.573$ \\
\hline \hline
\end{tabular}

\section{Land Cover Change Detection analysis and Landslide Events in year 2006 - 2014.}

In 2006 to 2014, a total of twelve landslide events were occured at Ulu Kelang, Selangor. Where two of incidents were recorded as major landslide events occurred in 2006 and 2008. The list of landslide events as shown in Table 5. In this study, only medium to large(major) scale landslides were involved. There were three locations identifies as landslide prone area in Ulu Kelang, Selangor which are Bukit Antarabangsa, Ukay Perdana and Kampung Pasir. All the location is in hillside area at an altitude of 100 to $200 \mathrm{~m}$ above sea level.

Based on LC change detection analysis, an increasing of build-up area with decreasing the green area contribute to landslide occurrences in Ulu Kelang, Selangor. From analysis, the increment of $14.143 \%$ build up areas from $5.322 \mathrm{~km}^{2}$ into $7.58 \mathrm{~km}^{2}$ shows that expanded of urban area, especially a residential area. This factor directly affects the degradation of green areas which are forest and vegetation areas. Based on landslide analysis in 2006 to 2014, about $91.66 \%$ landslide events were affected build up area (residential area and road). Where the initial landslide was occurred at green areas, then affected to nearby build up areas. There was one landslide incident has occurred at developing area and affected to nearby build up areas. All the landslide events occur in hillside areas. However no initial landslide recorded at build up area.
TABLE 5: LIST OF LANDSLIDE EVENTS IN ULU KELANG, SELAGOR IN $2006-2014$.

\begin{tabular}{|c|c|c|c|}
\hline No & Location & Date & $\begin{array}{l}\text { Scale of } \\
\text { Landslide }\end{array}$ \\
\hline 1 & Kampung Pasir, Ulu Kelang & 31 May 2006 & Major \\
\hline 2 & $\begin{array}{l}\text { Condominium Wangsa Height, } \\
\text { Bukit Antarabangsa }\end{array}$ & 23 April 2008 & Medium \\
\hline 3 & $\begin{array}{l}\text { Taman Bukit Mewah, Bukit } \\
\text { Antarabangsa }\end{array}$ & 6 Dis 2008 & Major \\
\hline 4 & $\begin{array}{l}\text { Wangsa Height, Bukit } \\
\text { Antarabangsa }\end{array}$ & 19 Sept 2009 & Medium \\
\hline 5 & $\begin{array}{l}\text { Jalan Wangsa } 7 \text {, Bukit } \\
\text { Antarabangsa }\end{array}$ & 19 Sept 2009 & Medium \\
\hline 6 & $\begin{array}{l}\text { Ukay Club Villa, Taman Kelab } \\
\text { Ukay }\end{array}$ & 9 April 2010 & Medium \\
\hline 7 & $\begin{array}{l}\text { Jalan Wangsa } 1 \text {, Bukit } \\
\text { Antarabangsa }\end{array}$ & $\begin{array}{l}1 \text { August } \\
2010\end{array}$ & Medium \\
\hline 8 & $\begin{array}{l}\text { Jalan Ukay Perdana } 1 / 8 \text {, Ukay } \\
\text { Perdana }\end{array}$ & 21 May 2011 & Medium \\
\hline 9 & $\begin{array}{l}\text { Taman Bukit Jaya, Bukit } \\
\text { Antarabangsa }\end{array}$ & 21 June 2011 & Medium \\
\hline 10 & Ukay Perdana & Feb 2011 & Medium \\
\hline 11 & Jalan UP 4, Ukay Perdana. & May 2012 & Medium \\
\hline 12 & Jalan UP1/5, Ukay Perdana & 27 Oct 2014 & Medium \\
\hline
\end{tabular}

By referred to Figure 5, there were eleven incidents of landslide events were affected residential area and road which were the landslide is initially started from nearby green area. This incident shows that build up area in hillside was influence the instability soil structure in surrounding area. This indicate that build up area was strongly affected by landslides especially in hillside areas. Although most of initial landslides occur from nearby green area.

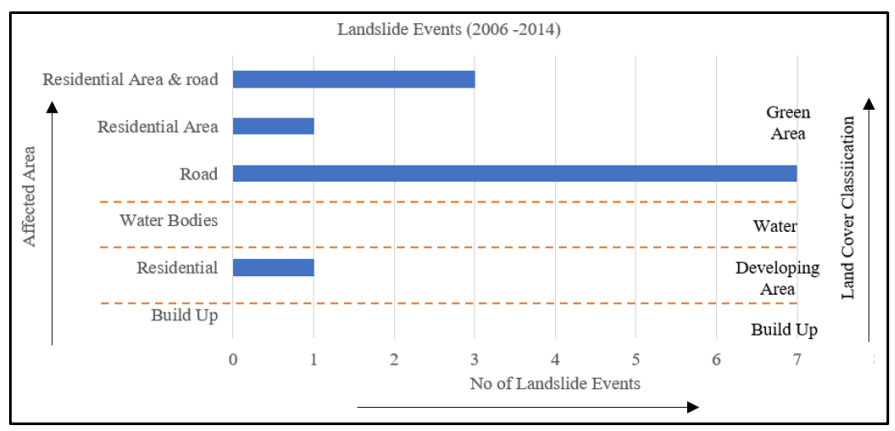

Figure 5: Landslide Events recorded in Ulu Kelang, Selangor in 2006 to 2014 .

The discussion shows that $\mathrm{LC}$ change detection is important in monitoring and prediction landslide occurrences by investigate the LC changes with landslide activity. LC change detection can be considered as an analysis to determine susceptibility index of landslide events in LC context. There were similar studies have shown the LC changes was influence the landslide susceptibility [21][16][22]. Thus, all development should be well planned and organized based on the aspects that led to the occurrence of landslides.

\section{CONCLUSIONS}

Based on the processing of the satellite image, the application of ArcMap 10.2.2 software was a very practical way to analyze the LC change detection and monitor the landslide. In this 
study, SPOT 5 images were used to obtain LC maps for the year 2005 and 2014. The LC classification using Maximum likelihood supervised classification. It could display a highquality image to create a map and to visualize it. The overall classification accuracy for images is $95 \%$ and $93 \%$ in the year 2005 and 2014, respectively. The Kappa quality is showed a very good quality where the values were 0.929 and 0.898 for both SPOT-5 images. According to the result of classification, the green areas were decreasing about $8.432 \%$ from year 2004 to 2014 , where degraded from $9.168 \mathrm{~km}^{2}$ into $7.822 \mathrm{~km}^{2}$. While Build up area increased by $14.143 \%$ due to human activities. From the LC change detection and landslide events analysis, the result obtained that most of landslide incidents have affected the build up area was starting from nearby green area due to instability soil structure in surrounding area especially in hillside area. The increment of build-up areas and decrement of green area were showed that LC is an important contributing factor in the occurrence of landslides.

\section{ACKNOWLEDGEMENT}

The authors would like to thank Faculty of Electrical Engineering, Universiti Teknologi MARA (UiTM) for their valuable support. This research is partly funded by the Malaysian Government through UiTM under 600-IRMI 5/3/GIP (042/2019). We are grateful to the Malaysian Space Agency (MYSA) for providing the SPOT 5 Satellite images.

\section{REFERENCES}

[1] Kaixiang Zhang, Xueling Wu, Ruiqing Niu, Ke yang and Lingran Zhoa, "The assessment of landslide susceptibility mapping using random forest and decision tree methods in the Three Gorges Reservior area, China," Environ Earth Sci., 2017.

[2] Ismail Elmahdy Samy, Maged Mahmoud Marghany and Mohamed Mostafa Mohamed, "Landslide Modelling and Analysis using Remote Sensing and GIS: A case study of Cameron Highland, Malaysia," Journal of Geomatics ISG. 8(2) 2014.

[3] Marco Scaioni, Laura Longoni, Valentina Melillo and Monica Papini, "Remote Sensing for Landslide Investigations: An Overview of Recent Achievements and Perspectives," Remote Sens., 6, 1, 2014.

[4] Simon Plank, André Twele and Sandro Martinis, "Landslide Mapping in Vegetated Areas Using Change Detection Based on Optical and Polarimetric SAR Data," Remote Sens. 8, 307, 2016.

[5] Kwong-Fai A. LO, Hui-Chung Yeh and Shou-Hung CHEN, "Landslide Detection Using Satellite Remote Sensing Imagery", IJDR, 5(4), 4237-4241, 2015.

[6] Chaoying Zhao and Zhong Lu, "Remote Sensing of Landslides-A Review," Remote Sens. 10(279), 2018.

[7] Zhongbin Li, Wenzhong Shi, Soe W. Myint,Ping Lu, Qunming Wang, "Semi-automated landslide inventory mapping from bi temporal aerial photographs using change detection and level set method" Remote Sens Environ 175, 215-230, 2016.

[8] Rohan Kumar and R. Anbalagan, "Remote sensing and GIS based artificial neural network system for landslide susceptibility mapping", IEEE International Geoscience and Remote Sensing Symposium (IGARSS), IEEE Conference Publication, Milan, Italy, 2015.

[9] Omar E. Mora, M. Gabriela Lenzano, Charles K. Toth, Dorota A. Grejner Brzezinska and Jessica V. Fayne, "Landslide Change Detection Based on Multi-Temporal Airborne LiDAR-Derived DEMs", Geosciences, 8(23), 2018.

[10] Sara Salehi and Mohammad Javad Valadan Zoej, "Unsupervised change detection based on improved Markov random field technique using multichannel synthetic aperture radar images", J. Appl. Remote Sens. 083591-1, 8, 2014.

[11] Zhongbin Lia, Wenzhong Shi, Ping Lu, Lin Yan, Qunming Wang and Zelang Miao. "Landslide mapping from aerial photographs using change detection-based Markov random field", Remote Sens Environ $187,76-90,2016$.

[12] Tesfa Gebrie Andualem, Gizew Belay and Adebabay Guadie, "Land Use Change Detection Using Remote Sensing Technology", J Earth Sci Clim Change, 9:10, 2018.

[13] Muhammad Hadi Saputra and Han Soo Lee, "Prediction of Land Use and Land Cover Changes for North Sumatra, Indonesia, Using an Artificial-Neural-Network-Based Cellular Automaton", Sustainability, 11, 3024, 2019.

[14] Shivangi Mishra, Priyanka Shrivastava and Priyanka Dhurvey, "Change Detection Techniques in Remote Sensing: A Review", International Journal of Wireless and Mobile Communication for Industrial Systems, Vol. 4, No. 1, pp.1-8, 2017.

[15] Liping C, Yujun S and Saeed S, "Monitoring and predicting land use and land cover changes using remote sensing and GIS techniques-A case study of a hilly area, Jiangle, China”. PLoS ONE 13(7): e0200493, 2018.

[16] Lixia Chen, Zizheng Guo, Kunlong Yin, Dhruba Pikha Shrestha, and Shikuan Jin, "The influence of land use and land cover change on landslide susceptibility: a case study in Zhushan Town, Xuan'en County (Hubei, China)", Nat. Hazards Earth Syst. Sci., 19, 2207-2228, 2019.

[17] Paweł Kroh, "Analysis of land use in landslide affected areas along the Łososina Dolna Commune, the Outer Carpathians, Poland", Geomatics, Natural Hazards and Risk, 8:2, 863-875, 2017.

[18] Lea Tien Tay, Mutasem Sh. Alkhasawneh, Umi Kalthum Ngah and Habibah Lateh, "Landslide hazard mapping of Penang Island using dominant factors", IEEE 2nd International Symposium on Telecommunication Technologies (ISTT), Langkawi, Malaysia, 2014.

[19] Zulkiflee Abd Latif, Siti Nur Afiqah Aman and Biswajeet Pradhan, "Landslide Susceptibility Mapping Using Lidar Derived Factors and Frequency Ratio Model: Ulu Kelang Area, Malaysia" IEEE 8th International Colloquium on Signal Processing and its Applications (CSPA) Melaka, Malaysia, 2012.

[20] James R. Anderson, Ernest E. Hardy, John T. Roach and Richard E. Witmer, "A Land Use and Land Cover Classification System For Use With Remote Sensor Data", Geological Survey Professional Paper 964, United States Government Printing Office, Washington ,1976.

[21] Nur Syahira and Noradila Rusli, "Analysis of Landslide Prediction As Related To Land use Changes In Perlis", Geomatics Research Innovation Competition Gric, Vol 1, 2017.

[22] J. H. Abdul kareema, B. Pradhan, W.N.A. Sulaiman, N.R.J amil, "Prediction of spatial soil loss impacted by long-term land-use/landcover change in a tropical watershed", Geoscience Frontiers Volume 10, Issue 2, Pages 389-403, March 2019. 